\title{
Clinical and endocrinological investigations on superovulation induced in heifers by human menopausal gonadotrophin
}

\author{
A. Lauria, A. R. Genazzani*, O. Oliva $\dagger$, P. Inaudi*, F. Cremonesi, \\ C. Monittola* and G. Aureli
}

Istituto di Anatomia degli Animali Domestici con Istologia ed Embriologia ed $†$ Istituto di Ostetricia e Ginecologia Veterinaria dell'Università di Milano, Via Celoria 10, 20133 Milano, and ${ }^{*}$ Cattedra di Patologia Ostetrica e Ginecologica dell'Università di Cagliari, Italy

\begin{abstract}
Summary. After an i.v. injection of human menopausal gonadotrophin (hMG), three components of the disappearance time in heifers were found for immunoreactive $\mathrm{LH}$ (half-life 13.8-1020 min) and immunoreactive FSH (half-life 21·3-1090 min). When heifers were treated daily with hMG from Days 9,10 or 11 of the cycle for 3 or 5 days, a total dose of 1350 i.u. FSH induced $10 \cdot 2 \pm 2.5$ (mean \pm s.d.) corpora lutea (CL) in 6 animals and 13 persistent follicles in 4 animals, while a total dose of 2100 i.u. FSH induced $14 \cdot 3 \pm 1.5 \mathrm{CL}$ in 6 heifers and there were no persistent follicles. Nine heifers treated with a single i.m. injection of 1500 i.u. PMSG exhibited $11.4 \pm$ 8.6 CL with 17 persistent follicles in 7 animals. Progesterone concentrations rose significantly faster and the oestradiol drop was more rapid after oestrus in heifers treated with hMG than in those treated with PMSG. These results demonstrate that stimulation of the ovarian follicles of heifers is more homogeneous when hMG is used.
\end{abstract}

\section{Introduction}

The induction of a correct, repeatable superovulation in heifers and cows to be used as donors for embryo transfer is in some respects still open to discussion (Moor, Cahill \& Stewart, 1980). Although studies on superovulation in cattle have made progress in recent years and satisfactory results can be obtained, the variability of the response to superovulatory stimulation still poses limits to the advantages of embryo transfer (Sreenan \& Beehan, 1976; Betteridge, 1977; Saumande, Chupin, Mariana, Ortavant \& Mauleon, 1978). It is generally agreed that the success of superovulation is affected by various factors such as the individual response, the physiological state of the animal at the time of treatment, age, breed, season and number of consecutive stimulations. It is also accepted that a very important role is played by the type of gonadotrophin used and the ratio of its effective FSH-like and LH-like biological activities on the ovarian structures (Gordon, 1975).

Numerous studies have been published on superovulation in heifers and cows using porcine or equine pituitary FSH (Schams et al., 1978; Danner, Oxender, Fogwell \& Douglas, 1979) or pregnant mare serum gonadotrophin (PMSG) (Schams et al., 1978; Aureli, Oliva \& Lauria, 1979; Newcomb, Christie, Rowson, Walters \& Bousfield, 1979; Saumande, 1980). Only limited information is available at present on the use of human menopausal gonadotrophin (hMG) to induce superovulation in cattle (Newcomb, 1980). 
The aim of the present work was to study both the clinical and endocrinological effects of ovarian stimulation of heifers with $\mathrm{hMG}$ to determine whether the use of this gonadotrophin can be used to advantage in embryo transfer practice.

\section{Materials and Methods}

\section{Animals}

The 23 Friesian heifers were 15-18 months old, clinically normal and experiencing regular cycles. Two of the heifers were used for evaluation of hMG half-life. The remaining 21 heifers were divided randomly into three groups. The 6 heifers in Group 1 were treated on Day 9, 10 or 11 of the cycle (Day $0=$ day of oestrus) with an i.m. injection of 600 i.u. FSH (8 vials of Pergonal 500; Serono) followed 24 and $48 \mathrm{~h}$ later by another two doses of 375 i.u. FSH (5 vials of Pergonal 500). The total dose received by each animal was therefore 1350 i.u. FSH. Starting from the same period of the cycle, the 6 heifers in Group 2 received i.m. 300 i.u. FSH equivalent (4 vials of Pergonal 500) twice daily for 2 days and 150 i.u. FSH twice daily for the following 3 days. The total dose received by each animal was therefore 2100 i.u. FSH. The 9 heifers in Group 3 received a single i.m. injection of 1500 i.u. PMSG (Folligon, Intervet) on Days 9, 10 or 11 of the cycle.

On the 3 rd day after the first injection, $500 \mu \mathrm{g}$ cloprostenol, a PGF-2 $\alpha$ analogue (Estrumate: I.C.I.), were administered i.m. to the animals in all 3 groups to induce oestrus. At oestrus, the animals received 2 doses of 1000 i.u. hCG (Profasi, Serono), $24 \mathrm{~h}$ apart. All animals were frequently checked clinically. The number of corpora lutea was evaluated by rectal palpation under epidural anaesthesia by two skilled operators.

Ten heifers were artificially inseminated and fertilized eggs were collected non-surgically on Day 8, and used for non-surgical transfer to synchronized recipients using a method developed in our laboratory (Oliva \& Lauria, 1981) or frozen in liquid nitrogen. Peripheral blood samples were collected twice daily from each animal starting several days before the beginning of treatment, until the 9 th day after oestrus, to determine progesterone and oestradiol concentrations.

\section{Hormone assays}

Procedure. For the radioimmunoassay of oestradiol and progesterone (Inaudi \& Genazzani, 1980), chromatographically pure standard hormones were purchased from Vister (Italy), tritiated hormones from NEN (Boston, U.S.A.) and antisera from CEA-IRE-SORIN (Italy). Plasma (1.5 ml) was extracted with $15 \mathrm{ml}$ ethyl ether and, after separation of the aqueous phase, dried under nitrogen at $40^{\circ} \mathrm{C}$. The dry residue was redissolved in $0.8 \mathrm{ml}$ Tris- $\mathrm{HCl}$ buffer, $\mathrm{pH}$ 7.4, containing $0.01 \mathrm{M}$-EDTA and $\mathrm{NaN}_{3}(\mathrm{~g} / \mathrm{l})$. Two $0.3-\mathrm{ml}$ aliquots of the redissolved samples were used for oestradiol assay. Of the remaining volume $0.1 \mathrm{ml}$ was diluted to $1.3 \mathrm{ml}$ with the same buffer, and two $0.3-\mathrm{ml}$ aliquots were used for progesterone assay. The oestradiol assay required a 1 -h preincubation of the samples with the antibody before addition of the labelled hormone (1200-1300 d.p.m./tube). The working dilution of the oestradiol antiserum was $1: 150000$ and that of the progesterone antiserum was $1: 25000$. After $18-20 \mathrm{~h}$ incubation for oestradiol and $12-14 \mathrm{~h}$ for progesterone, dextran-coated charcoal $(1 \mathrm{mg} / \mathrm{ml})$ was used to separate free from antibody-bound hormone.

Validation. The validation details, which have been extensively described in a previous paper (Inaudi \& Genazzani, 1980), showed good precision and a very high sensitivity. The within- and between-assay variations, expressed as the coefficient of variation (CV) were 4.8 and $9.2 \%$ for oestradiol and 10.0 and $14.2 \%$ for progesterone. The theoretical sensitivity, evaluated as described elsewhere (Inaudi \& Genazzani, 1980), was $0.11 \mathrm{pg}$ oestradiol/tube and $1.02 \mathrm{pg}$ progesterone $/ \mathrm{ml}$. 


\section{Evaluation of the half-life of $h M G$}

Two heifers were used as follows: on Day 11 of the cycle, each animal received an intravenous injection of 20 vials of Pergonal (1500 i.u. FSH plus 1500 i.u. LH). Peripheral blood samples were than collected into heparinized ampoules at $5,10,15,20,30,45,60,90$, $120,150,180,210$ and $240 \mathrm{~min}$, and 5, 6, 7, 8, 9, 10,11,12,18, 24, 30, 36, 48, 60, and $72 \mathrm{~h}$ after the injection. All samples were centrifuged immediately after collection, and the plasma was divided into $1-\mathrm{ml}$ samples and stored at $-20^{\circ} \mathrm{C}$ until determination of the $\mathrm{FSH}$ and $\mathrm{LH}$ concentrations with kits purchased from Biodata (Italy). Bovine contamination of immunoreactive LH and FSH (preinjection levels) was determined in 8 different samples obtained in the same animals $2-3$ days before the study.

The disappearance rate of hMG was calculated as follows: after subtraction of the basal (preinjection) values, the plasma concentrations of hLH and hFSH were plotted on semilogarithmic paper and appeared curvilinear. The curves are described by an equation of two or more exponential terms. To calculate the equation, and consequently the half-time relative to the different components, the 'curve-stripping' method was used (Oppenheimer \& Gurpide, 1979). The terminal portion of the curve was represented by a straight line which, when extrapolated for $t=0$, gives the value of the plasma concentrations $\left(C_{0}\right)$ for the exponential term relative to this part of the curve. The removal rate constant $(\lambda)$ which characterizes the slope of the curve was evaluated graphically. The exponential term thus defined was then resolved and subtracted from the $\mathrm{C}$ values corresponding to the different $\mathrm{t}$ values; the data obtained, plotted as a function of $t$ on semilogarithmic paper, gave a curved line, from which $\mathrm{C}_{0}$ and $\lambda$ relative to the second exponential can be determined in the same manner as described above. The step was repeated to evaluate further exponential terms.

\section{Results}

The mean ( \pm s.d.) preinjection plasma values of immunoreactive $\mathrm{LH}$ for 8 samples from each of 2 animals were $1.44 \pm 0.37 \mathrm{mi} . \mathrm{u}$. $\mathrm{hLH} / \mathrm{ml}$ and $3.66 \pm 0.45 \mathrm{mi} . \mathrm{u}$. $\mathrm{hFSH} / \mathrm{ml}$. After the pulse injection of hMG (1500 i.u.) the semilogarithmic plot of the plasma concentrations of hLH and hFSH against time, after subtraction of basal levels from each observation, did not yield a straight line and a curvilinear decline of hLH and hFSH was then analysed (Text-fig. 1). The best fit was obtained using a function with three exponential terms. For the hLH, the three components showed half-life values for Heifers 118 and 702 , of 13.8 and $20 \mathrm{~min}, 130$ and 164 min, and 875 and 1020 min respectively. The equations of the two curves were: $\mathrm{C}=19 \cdot 5 e^{-0.034 t}$ $+22 e^{-0.0048 \mathrm{t}}+16 \cdot 5 e^{-0.0007 t}$ and $\mathrm{C}=18 \cdot 6 e^{-0.053 \mathrm{t}}+24 \cdot 3 e^{-0.0042 \mathrm{t}}+16 \cdot 2 e^{-0.00078 \mathrm{t}}$. For hFSH, the values of the half-life relative to the three components were 21.3 and $24.5 \mathrm{~min}, 179$ and $200 \mathrm{~min}$, and 1075 and $1090 \mathrm{~min}$, respectively, for the same 2 heifers. The equations of the relative curve were: $\mathrm{C}=58 e^{-0.028 \mathrm{t}}+27.5 e^{-0.0035 \mathrm{t}}+29 \cdot 5 e^{-0.00065 t}$ and $\mathrm{C}=55 e^{-0.032 \mathrm{t}}+42 e^{-0.0039 \mathrm{t}}+$ $29 e^{-0 \cdot 00063 t}$.

All the animals injected with hMG (Groups 1 and 2 ) responded very well to the stimulation. Clinical examination revealed that the treatment induced a gradual development of numerous follicles which attained normal size, in all cases. Individual variability was markedly low. In the days after oestrus, a difference in behaviour was observed between the animals of Group 1 and Group 2: none of the animals in Group 2 showed persistent follicles; there were $14.3 \pm 1.5$ (s.d.) corpora lutea and each corpus luteum was clearly appreciable by rectal palpation. In the heifers of Group 1 , the mean \pm s.d. number of corpora lutea was $10 \cdot 2 \pm 2 \cdot 5$, but 4 animals also showed persistent follicles (13 in all). Although the mean degree of superovulation induced by PMSG (Group 3) was satisfactory, the individual variability was very high, the effect ranging from almost none to excessive reaction and enormous enlargement due to the large number and 


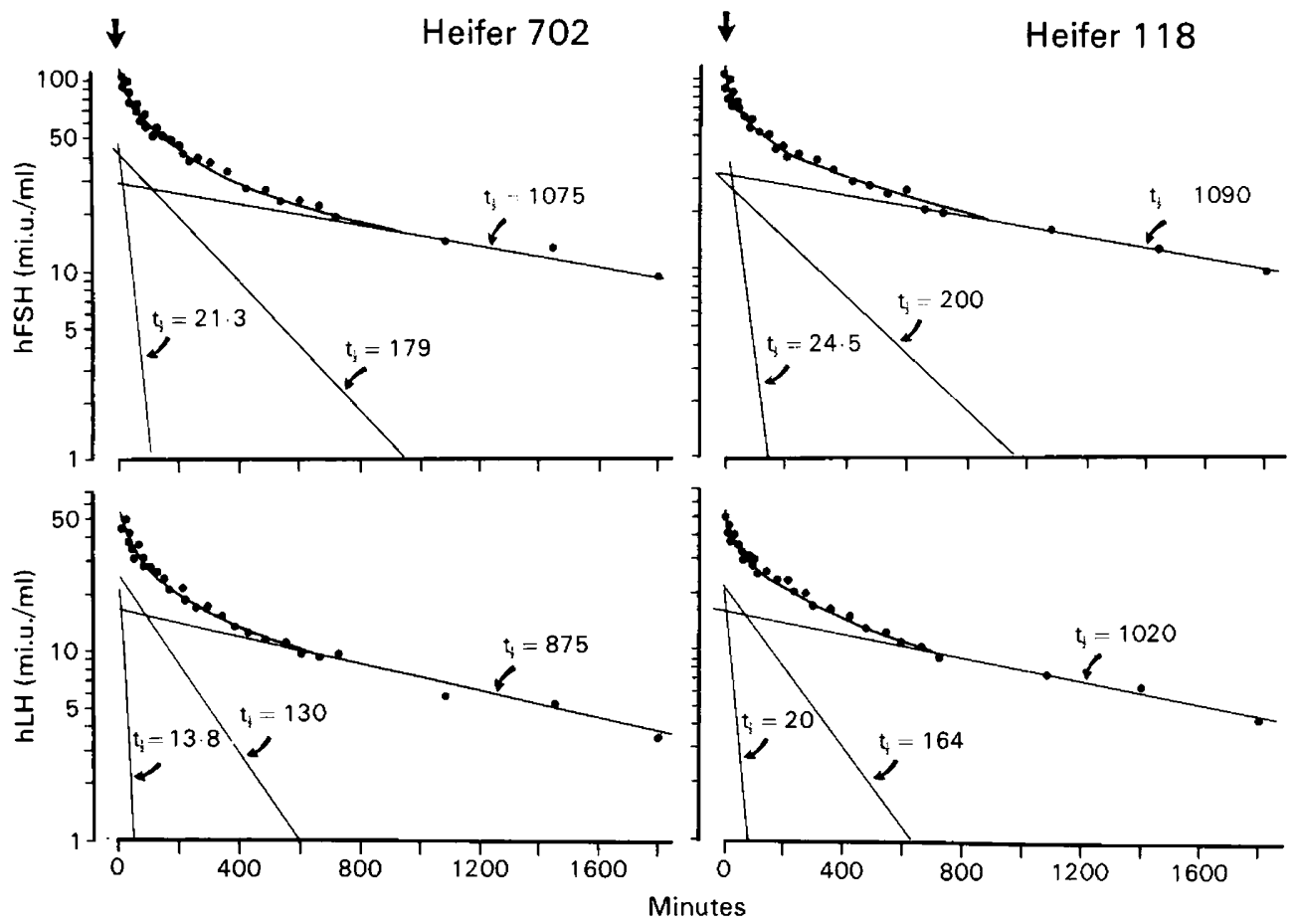

Text-fig. 1. Disappearance time for immunoreactive hLH and hFSH in two cyclic heifers injected (arrow) with a single dose of 20 vials (1500 i.u.) of hMG (Pergonal 500). The curvilinear decline of the injected gonadotrophins was analysed by the method of 'curve stripping' (see 'Materials and Methods').

unusual size of some follicles that did not ovulate. The mean number of corpora lutea was $11.4 \pm 8.6$ (s.d.) and a total of 17 persistent follicles was found in 7 animals.

A close relationship was found between the number of corpora lutea and the embryos collected from the inseminated animals (Table 1).

Table 1. Relationship between corpora lutea and collected embryos in heifers induced to superovulate

\begin{tabular}{lccccc}
\hline & & & \multicolumn{2}{c}{ No. of embryos } \\
\cline { 3 - 5 } Group & $\begin{array}{c}\text { No. of } \\
\text { heifers }\end{array}$ & $\begin{array}{c}\text { No. of } \\
\text { corpora lutea }\end{array}$ & Collected & $\begin{array}{c}\text { Morphologically } \\
\text { normal }\end{array}$ \\
\hline 1 (hMG 3 days) & 3 & 33 & 21 & 13 \\
2 (hMG 5 days) & 3 & 43 & 24 & 19 \\
3 (PMSG) & 4 & 51 & 30 & 20 \\
\hline
\end{tabular}

The pattern of plasma hormone levels was in agreement with the clinical examination. HMG induced good follicular stimulation, followed by a very rapid increase in plasma progesterone to plateau levels, the maximum value being reached on Day 7 after oestrus (Text-fig. 2). Furthermore, oestradiol dropped sharply between Day 4 and Day 7, simultaneously with the rise in progesterone. 


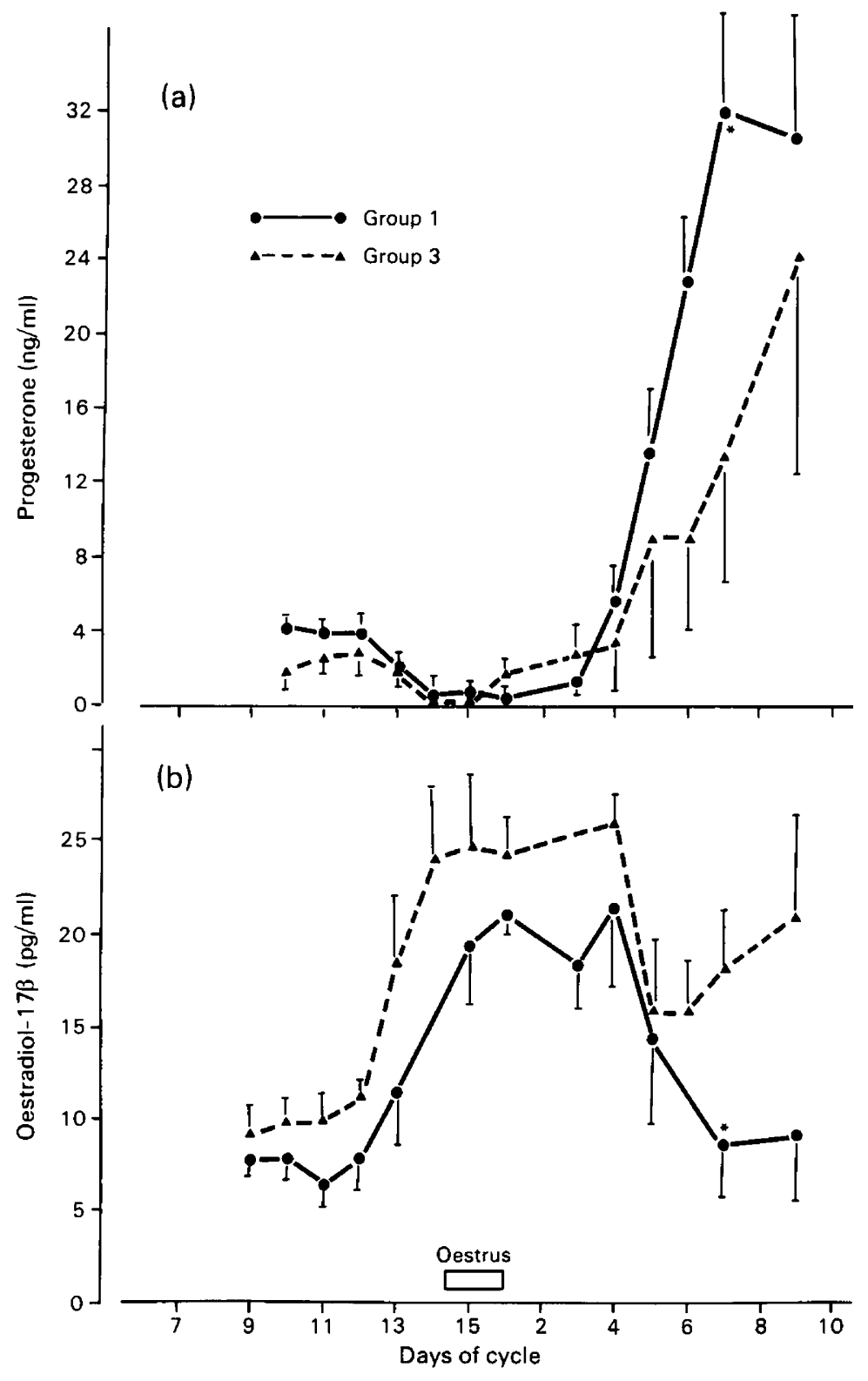

Text-fig. 2. Plasma concentrations (mean \pm s.e.m.) of (a) progesterone and (b) oestradiol-17 $\beta$ in 6 heifers in which superovulation was induced with hMG (Group 1) and 9 heifers stimulated with PMSG (Group 3). *Significantly different from Group 3 value, $P<0.05$.

PMSG also induced a marked increase in plasma progesterone to very high levels, but the rise was slower, reaching maximum values on Days 9-10. On Day 7, the difference between the mean progesterone values of hMG- and PMSG-treated heifers was statistically significant $(P<$ $0.05)$.

The mean oestradiol values of the animals in Group 3 were generally significantly higher 
than those of heifers receiving in Groups 1 and 2, and the hormone patterns was much more irregular (Text-fig. 2).

\section{Discussion}

The present results show that the disappearance of $\mathrm{hLH}$ and $\mathrm{hFSH}$ from the circulation of clinically normal heifers is best described by an equation composed of three exponential terms. The very short half-life relative to the first component $(13 \cdot 8-20 \mathrm{~min}$ for $\mathrm{hLH}$ and $21 \cdot 3-24.5$ min for hFSH) probably reflects the distribution in the peripheral circulation, and consequently the second (130-164 $\mathrm{min}$ for $\mathrm{hLH}$ and 179-200 $\mathrm{min}$ for hFSH) and third components (875-1020 $\mathrm{min}$ for hLH and 1075-1090 min for hFSH) can be considered to represent the half-life of hMG in cattle. These two components of hMG half-life can be compared with the 2 components of PMSG half-life, these latter being 40-50 h (first component) and 118-123 h (second component) (Menzer \& Schams, 1979). The much shorter half-life of hMG, combined with its high biological standardization and purification, suggests the possibility of inducing a much more correct and controllable ovarian stimulation.

The half-life of immunoreactive LH in Pergonal is shorter than that of FSH. This might influence follicular maturation favourably, as has been suggested by the findings of Richards et al. (1976) who demonstrated an inhibitory effect of LH on the number of granulosa receptors for FSH, LH and oestradiol in developing follicles in the rat. It is therefore possible that the faster disappearance of the LH component of hMG could enhance the FSH activity on follicular structures.

The progesterone and oestradiol patterns are also in favour of this hypothesis. In fact the short half-life of hMG can be related to the more homogeneous and rapid increase of progesterone during the luteal phase and the simultaneous decrease of oestradiol, indicating a more synchronized effect on the activation and maintenance of follicular maturation. The slower rise of progesterone and the higher levels and irregular pattern of plasma oestradiol induced by PMSG were probably due to its prolonged stimulatory action on follicular maturation.

The hormonal results are supported by the clinical examinations, which showed a gradual development of follicles and corpora lutea in the heifers in which superovulation was induced by hMG, and more irregular development in those treated with PMSG. There was a great difference in the range of response to PMSG and hMG. The lower variability of the superovulatory effect of hMG is probably due both to its short half-life and to a more 'paraphysiological' response of the ovarian structures to the gonadotrophin which has a constant 1:1 FSH/LH ratio, but a shorter half-life of the LH component. The clinical findings also show that, in all 3 groups, the hormone stimulation induced the formation of about the same number of follicles per animal, although some follicles in heifers in Groups 1 and 3 did not ovulate. In Group 3 heifers there was probably a stronger and more prolonged stimulation by PMSG which induced and maintained the maturation of new follicles for a longer period. In Group 1, however, stimulation by hMG could have been insufficient.

At present it is difficult to establish whether the improved results obtained in this experiment with hMG were due to the higher total dose of Pergonal (2100 i.u. FSH) or to the treatment schedule ( 2 injections daily for 5 days, instead of 1 injection daily for 3 days). On the basis of both clinical and endocrinological findings, we are in favour of the latter possibility which we hope to verify in subsequent experiments.

This work was supported by the Consiglio Nazionale delle Ricerche project 'Biology of Reproduction'. We thank Dr Manlio Barbetti, Istituto Farmacologico Serono, Rome, for providing us with the Pergonal used in this study and Dr. Guido Antoni, Research Center of the SCLAVO Institute, Siena, for assistance with the half-life calculations. 


\section{References}

Aureli, G., Oliva, O. \& Lauria, A. (1979) Trasferimento degli embrioni nel bovino. Atti Soc. ital. Sci. vet. 23, 54-63.

Betteridge, K.J. (1977) Techniques and results in cattle: superovulation. In Embryo Transfer in Farm Animals, pp. 1-9. Ed. K. J. Betteridge. Dept Agriculture, Ottawa, Canada; Monograph No. 16.

Danner, M.L., Oxender, W.D., Fogwell, R.L. \& Douglas, R.H. (1979) Use of an equine pituitary extract with and without HCG to superovulate cows. Theriogenology 11, 96.

Gordon, I. (1975) Problems and prospects in cattle eggs transfer. Irish vet. J. 29, 21-30.

Inaudi, P. \& Genazzani, A.R. (1980) Simultaneous plasma radioimmunoassay of oestradiol, progesterone, 17-hydroxyprogesterone, testosterone and androstenedione in farm animals. $J$. nucl. Med. all. Sci. 24, 127-133.

Menzer, C. \& Schams, D. (1979) Radioimmunoassay for PMSG and its application to in-vivo studies. $J$. Reprod. Fert. 55, 339-345.

Moor, R.M., Cahill, L.P. \& Stewart, F. (1980) Ovarian stimulation for egg production as a limiting factor of egg transfer. Proc. 9th Int. Congr. Anim. Reprod. \& A.I., Madrid 1, 43-58.

Newcomb, R. (1980) Investigations of factors affecting superovulation and non-surgical embryo recovery from lactating British Friesian cows. Vet. Rec. 106, 48-52.

Newcomb, R., Christie, W.B., Rowson, L.E.A., Walters, D.E. \& Bousfield, W.E.D. (1979) Influence of dose, repeated treatment and batch of hormone on ovarian response in heifers treated with PMSG. J. Reprod. Fert. 56, 113-118.
Oliva, O. \& Lauria, A. (1981) A new catheter for non-surgical embryo transfer in cattle. Atti Soc. ital. Sci. vet. 35, 480-481.

Oppenheimer, J.H. \& Gurpide, E. (1979) Quantitation of the production, distribution and interconversion of hormones. In Endocrinology, vol. 3, pp. 2029-2036. Ed. L. I. De Groot. Grune and Stratton, New York.

Richards, J.S., Ireland, J.J., Rao, M.C., Bernath, G.A., Midgley, A.R. \& Reichert, L.E. (1976) Ovarian follicular development in the rat: hormone receptor regulation by $\mathrm{E}_{2}, \mathrm{FSH}$ and LH. Endocrinology 99, 1562-1570.

Saumande, J. (1980) Concentrations of luteinizing hormone, oestradiol-17 $\beta$ and progesterone in the plasma of heifers treated to induce superovulation. $J$. Endocr. 84, 425-437.

Saumande, J., Chupin, D., Mariana, J.C., Ortavant, R. \& Mauleon, P. (1978) Factors affecting the variability of ovulation rates after PMSG stimulation. In Control of Reproduction in the Cow, pp. 195-224. Ed. J. M. Sreenan. M. Nijhoff, The Hague.

Schams, D., Menzer, C.H., Schallenberger, E., Hoffmann, B., Hahn, J. \& Hahn, R. (1978) Some studies on pregnant mare serum gonadotrophin (PMSG) and on endocrine responses after application for superovulation in cattle. In Control of Reproduction in the Cow, pp. 122-143. Ed. J. M. Sreenan. M. Nijhoff, The Hague.

Sreenan, J.M. \& Beehan, D. (1976) Embryonic survival and development at various stages of gestation after bilateral egg transfer in the cow. J. Reprod. Fert. 47, $127-128$. 